CLINICAL STUDY

\title{
Associations of IGF1 and IGFBPs 1 and 3 with all-cause and cardiovascular mortality in older men: the Health In Men Study
}

\author{
Bu B Yeap ${ }^{1,2}$, S A Paul Chubb ${ }^{1,3}$, Kieran A McCaul ${ }^{4}$, Ken K Y Ho ${ }^{5}$, Graeme J Hankey ${ }^{1}$, Paul E Norman ${ }^{6}$ \\ and Leon Flicker ${ }^{1,4}$ \\ ${ }^{1}$ School of Medicine and Pharmacology, University of Western Australia, Perth, Western Australia, Australia, ${ }^{2}$ Department of Endocrinology and Diabetes \\ and ${ }^{3}$ PathWest Laboratory Medicine, Fremantle Hospital, Fremantle, Western Australia, Australia, ${ }^{4}$ WA Centre for Health and Ageing, Centre for Medical \\ Research, University of Western Australia, Perth, Western Australia, Australia, ${ }^{5}$ Centres for Health Research, Princess Alexandra Hospital, Brisbane, \\ Queensland, Australia and ${ }^{6}$ School of Surgery, University of Western Australia, Perth, Western Australia, Australia
}

(Correspondence should be addressed to B B Yeap who is now at School of Medicine and Pharmacology, Level 2, T Block, Fremantle Hospital, Alma Street, Fremantle, Western Australia 6160, Australia; Email: byeap@cyllene.uwa.edu.au)

\begin{abstract}
Objective: Circulating IGF1 declines with age while ill-health increases. Controversy remains whether differences in the levels of IGF1 and its binding proteins 1 and 3 (IGFBP1 and IGFBP3) determine health outcomes during ageing. We examined associations of IGF1, IGFBP1 and IGFBP3 with all-cause and cardiovascular mortality in older men.

Design: We conducted a prospective cohort study of community-dwelling men aged $\geq 70$ years.

Methods: Plasma collected at baseline (2001-2004) was assayed for total IGF1, IGFBP1 and IGFBP3. Incidence and causes of death from time of recruitment to 31 December 2008 were ascertained using the Western Australian Data Linkage System. Cox regression analyses were performed, adjusting for conventional cardiovascular risk factors.

Results: Among 3983 men followed for 5.2 years (median), 694 deaths occurred, 243 from cardiovascular disease (CVD). There was no difference in survival according to quintiles of IGF1. Increased IGFBP1 predicted increased all-cause mortality (highest versus lowest quintile: adjusted hazard ratio $(\mathrm{HR})=1.98,95 \%$ confidence interval $(\mathrm{CI})=1.52-2.57, P<0.001$ for trend) and increased cardiovascular mortality $(\mathrm{HR}=3.42$ (2.03-5.77), $P<0.001$ for trend). Decreased IGFBP 3 predicted increased all-cause mortality (lowest versus highest quintile: $\mathrm{HR}=1.57,95 \%$ $\mathrm{CI}=1.23-2.01, P=0.007$ for trend). Associations of IGFBP1 and IGFBP3 with all-cause mortality were not attenuated by adjustment for IGF1 levels.

Conclusions: In older men, higher IGFBP1 and lower IGFBP3 levels predict overall and CVD-related mortality, while IGF1 levels are not associated with mortality. Further studies are needed to clarify the underlying mechanisms by which IGFBP1 and IGFBP 3 levels are associated with mortality risk, and whether this occurs independently of IGF1.
\end{abstract}

European Journal of Endocrinology 164 715-723

\section{Introduction}

Ageing is associated with gradual deterioration in health and well-being, and with a range of endocrine changes which may contribute to disease. This includes a decline in $\mathrm{GH}$ secretion, resulting in a reduction in circulating insulin-like growth factor 1 (IGF1) $(1,2)$. In adults who are GH-deficient, GH replacement therapy raises IGF1 and improves body composition and markers of cardiovascular risk (3). In the absence of known pituitary disease, it is unclear whether the age-related decline in $\mathrm{GH}$ secretion and the related fall in IGF1 levels contribute directly to ill-health and mortality.

Observational studies examining associations between IGF1 and its binding proteins (IGFBPs) with cardiovascular risk and mortality have yielded inconsistent results. Lower IGF1 is generally associated with adverse risk factors for cardiovascular disease (CVD) (4-6) and with heart failure, ischaemic heart disease (IHD) and stroke (7-9). However, other studies have not shown comparable associations (10), or have correlated higher IGF1 levels with increased CVD risk $(11,12)$. Lower IGF1 has been associated with increased IHD mortality, and with CVD or all-cause mortality (13-15). By contrast, several studies have found no association of IGF1 levels with mortality (16-18), or reported that higher IGF1 levels predicted all-cause mortality (19). One study reported a U-shaped association of IGF1 with CVD mortality (20).

Circulating IGF1 is bound to carrier proteins, which regulate availability of IGF1 thus modulating its effect 
on target tissues. The large majority of circulating IGF1 is bound to IGFBP3 and acid-labile subunit (ALS) in a ternary complex (2). Higher IGFBP3 levels, which might reduce unbound or bioavailable IGF1, have been correlated with markers of increased cardiovascular risk $(6,8,11,12)$. In comparison, other studies found lower IGFBP3 was associated with increased risk of stroke and coronary events $(9,10)$. Data examining the association of IGFBP 3 with mortality are limited $(14,16)$. While IGFBP1 binds a relatively small fraction of circulating IGF1, its production is suppressed by insulin enabling variation of IGF1 bioavailability in response to metabolic demand $(2,21)$. Reduced IGFBP 1 is a marker of insulin resistance and metabolic syndrome (22-24). However, both lower and higher IGFBP1 levels have been associated with mortality $(13,17,18)$.

Thus, additional studies are needed to address this uncertainty and clarify whether low or high levels of IGF1 and IGFBPs are robust markers of all-cause or CVD-related mortality. Resolving these questions would help determine the feasibility of testing interventions that modulate levels of IGF1 to preserve health, particularly in older adults. We tested the hypothesis that IGF1, IGFBP1 and IGFBP3 levels are independent predictors of mortality in communitydwelling older men.

\section{Participants and methods}

\section{Study population}

Details of the Health In Men Study (HIMS) have been described in depth elsewhere (25). Briefly, 4263 community-dwelling men resident in metropolitan Perth, Western Australia, attended a study clinic between October 2001 and August 2004. These men were part of an earlier population-based sample of 12203 men screened for the presence of abdominal aortic aneurysm in 1996-1999, and were predominantly of Caucasian ethnicity. Demographic, medical and medications data were collected. Height (in $\mathrm{cm}$ ), weight (in $\mathrm{kg}$ ), waist and hip circumference (in $\mathrm{cm}$ ) and blood pressure were measured using standard procedures. An early morning blood sample was obtained. The Human Research Ethics Committee of the University of Western Australia approved the study protocol and all study participants gave their written informed consent.

\section{Definition of hypertension, dyslipidemia and diabetes}

Hypertension was defined as a recorded blood pressure $\geq 140 / 90$ or having a diagnosis of hypertension or receiving treatment for high blood pressure. Dyslipidemia was defined as having high-density lipoprotein $<0.9 \mathrm{mmol} / \mathrm{l}$, low-density lipoprotein $\geq 3.4 \mathrm{mmol} / \mathrm{l}$, triglycerides $\geq 1.8 \mathrm{mmol} / \mathrm{l}$ or total cholesterol $\geq 5.5 \mathrm{mmol} / \mathrm{l}$, or receiving lipid-lowering therapy. Men who had been diagnosed with diabetes, with reported use of glucose-lowering medication, or had a fasting glucose of $\geq 7 \mathrm{mmol} / \mathrm{l}$ or non-fasting glucose of $\geq 11.1 \mathrm{mmol} / \mathrm{l}$, were considered to have diabetes.

\section{Identification of men with pre-existing CVD}

Men with pre-existing CVD were identified from selfreported questionnaire data and from medical data obtained through the Western Australian Data Linkage System (WADLS) (26). Briefly, WADLS links together records from the Mental Health Information System, cancer register, death register and hospital morbidity data (which include codes for multiple medical diagnoses for all admissions to private and public hospitals). WADLS hospital records were flagged for myocardial infarction or IHD, using the International Classification of Diseases (ICD)/-10-AM codes in the range $\mathrm{I} 21-\mathrm{I} 25$, or with ICD-8, ICD-9 or ICD-9-CM diagnosis codes 410-414, or with Code of Surgical Operations (COSO) procedure code 304, International Classification of Procedures in Medicine (ICPM) codes 5-360 to 5-363, or ICD-9-CM procedure codes 36.x. For stroke and arterial diseases, the corresponding ICD10 codes were H34.1, I60, I61-I64 and I71.0, I71.2I71.9, I72-I74.

\section{Assessment of medical comorbidity}

We used the Charlson score (27) to determine the presence of significant medical comorbidity in our cohort. The score takes into account 17 common medical conditions that predict 1-year mortality: myocardial infarction, congestive heart failure, peripheral arterial disease, cerebrovascular disease, dementia, chronic pulmonary disease, connective tissue disease, ulcer disease, liver disease, diabetes (including diabetes with end organ damage), hemiplegia, renal disease, leukaemia, lymphoma, other tumours, metastatic tumours and AIDS. Medical diagnoses are weighted for severity and summed to provide a weighted index of medical comorbidity. Data were included from 1990 to the time of blood sampling, providing a measure of recent comorbidity.

\section{Laboratory assays}

Blood samples were collected at baseline (2001-2004) between 0800 and $1030 \mathrm{~h}$. Plasma was prepared immediately following phlebotomy and stored at $-80{ }^{\circ} \mathrm{C}$ until assayed. Biochemical and hormone assays were performed in the Biochemistry Department, PathWest Laboratory Medicine, Fremantle and Royal Perth Hospitals, Western Australia, as previously described (28). Briefly, total IGF1, IGFBP1 and IGFBP3 were 
assayed using reagent kits of single lot numbers from Diagnostics Systems Laboratories, Inc. (DSL, supplied by Beckman Coulter, Gladesville, NSW, Australia). The non-extraction IGF1 ELISA, the Total IGFBP1 ELISA and the Active IGFBP 3 ELISA kits were used. The assays were automated using a Grifols Triturus ELISA processor (Vital Diagnostics, Castle Hill, NSW, Australia). For measurement of IGF1, samples were pretreated with acid to displace IGF1 from binding proteins, followed by neutralisation and addition of binding inhibitors prior to assay. Between-run imprecision (coefficient of variation) was 12.2 and $8.6 \%$ at 117 and $216 \mathrm{ng} / \mathrm{ml} \mathrm{IGF1;}$ 8.6 and $5.2 \%$ at 3.1 and $49 \mathrm{ng} / \mathrm{ml}$ IGFBP1; and 16.8 and $4.4 \%$ at 540 and $4300 \mathrm{ng} / \mathrm{ml}$ IGFBP3. All assays were carried out on freshly thawed aliquots of EDTA plasma in a series of runs between January 2008 and February 2009.

\section{Ascertainment of deaths}

Occurrence of death was ascertained from time of recruitment to 31 December 2008. Primary cause of death was ascertained from WADLS mortality data. This dataset contains both the original death certificate and ICD codes generated from this data and other sources by the Australian Bureau of Statistics (ABS). Deaths in which IHD appeared in the text of part 1 of the death certificate (e.g. acute myocardial infarction, atherosclerotic heart disease and chronic IHD) were considered CVD-related deaths. Where ABS coding was available, records containing ICD-10 codes in the range I21-I25 were flagged. For CVD-related deaths, stroke and arterial disease were included as causes of death and additional codes were flagged for stroke (H34.1, I60 and I61-I64) and arterial diseases (I71.0, I71.2-I71.9 and I72-I74).

\section{Statistical analysis}

Data were analysed with the statistical package Stata, version 11.1 (StataCorp, College Station, TX, USA). Quantitative data are tabulated as mean \pm s.D. KaplanMeier plots of survival according to quintiles of IGF1, IGFBP1 and IGFBP3 were charted. Cox regression models were used to test the associations of IGF1, IGFBP1 and IGFBP3 with overall mortality. The reference group for each exposure-outcome model was chosen based on exploratory analyses using quintiles. For cause-specific mortality, CVD-related and non-CVDrelated deaths, cause-specific regression models were used (29). In the regression models, fasting status, age, body mass index (BMI), waist:hip ratio, smoking, hypertension, dyslipidemia, diabetes, prevalent CVD and medical comorbidities (Charlson Index) were examined as potential confounders using the "changein-estimate' method (30). Covariates were added to the model and retained if inclusion resulted in an appreciable change in HR.

\section{Results}

\section{Characteristics of the study population}

Results from 3983 men were included in the analysis and their baseline characteristics are shown in Table 1 . Mean age was 77 years. The prevalence of diabetes was $15.8 \%$, three quarters of the men had hypertension or dyslipidemia and just under half had a history of CVD. The number of men fasted at the time of blood sampling was 3113 (78.3\%) (see Supplementary Table 1, and section on supplementary data given at the end of this article). IGFBP1 levels were higher in fasted compared with non-fasted men, thus fasting status was included as a covariate in subsequent analyses. In the cross-sectional analysis of this cohort, IGF1 and IGFBP3 levels decreased with increasing age, while IGFBP1 levels increased (28).

\section{Associations of IGF1, IGFBP1 and IGFBP3 with overall mortality}

Median length of follow-up was 5.2 years (interquartile range 4.6-5.9 years). There were 694 deaths, of which 243 were CVD-related (35.0\%). Kaplan-Meier plots of cumulative mortality according to quintiles of IGF1, IGFBP1 and IGFBP3 are shown in Fig. 1. There was no difference in mortality according to quintiles of IGF1 (Fig. 1A). Men in the highest quintile of IGFBP1 had increased cumulative mortality (Fig. 1B). Men with IGFBP3 levels in the lowest quintile of values had increased mortality (Fig. 1C).

Table 1 Baseline characteristics of the study population.

\begin{tabular}{ll}
\hline Characteristics & Values \\
\hline Age (years; mean (s.D.)) & $77.05(3.61)$ \\
BMI (kg/m²; mean (s.D.)) & $26.55(3.61)$ \\
Waist circumference (cm; mean (s.D.)) & $99.20(10.06)$ \\
Waist:hip ratio (mean (s.D.) & $0.97(0.07)$ \\
IGF1 (ng/ml; mean (s.D.)) & $141.45(58.88)$ \\
IGFBP1 (ng/ml; mean (s.D.)) & $26.83(20.81)$ \\
IGFBP3 (ng/ml; mean (s.D.)) & $3785.24(904.63)$ \\
Charlson index (\%) & \\
0 & 55.07 \\
1 & 16.21 \\
2 & 13.93 \\
3 & 6.77 \\
4 & 3.19 \\
$5+$ & 4.85 \\
Smoking (\%) & \\
Non-smoker & 33.32 \\
Former smoker & 61.60 \\
Current smoker & 5.08 \\
Diabetes (\%) & 15.83 \\
Dyslipidemia (\%) & 75.48 \\
Hypertension (\%) & 76.15 \\
Previous CVD (\%) & 43.54 \\
\hline
\end{tabular}



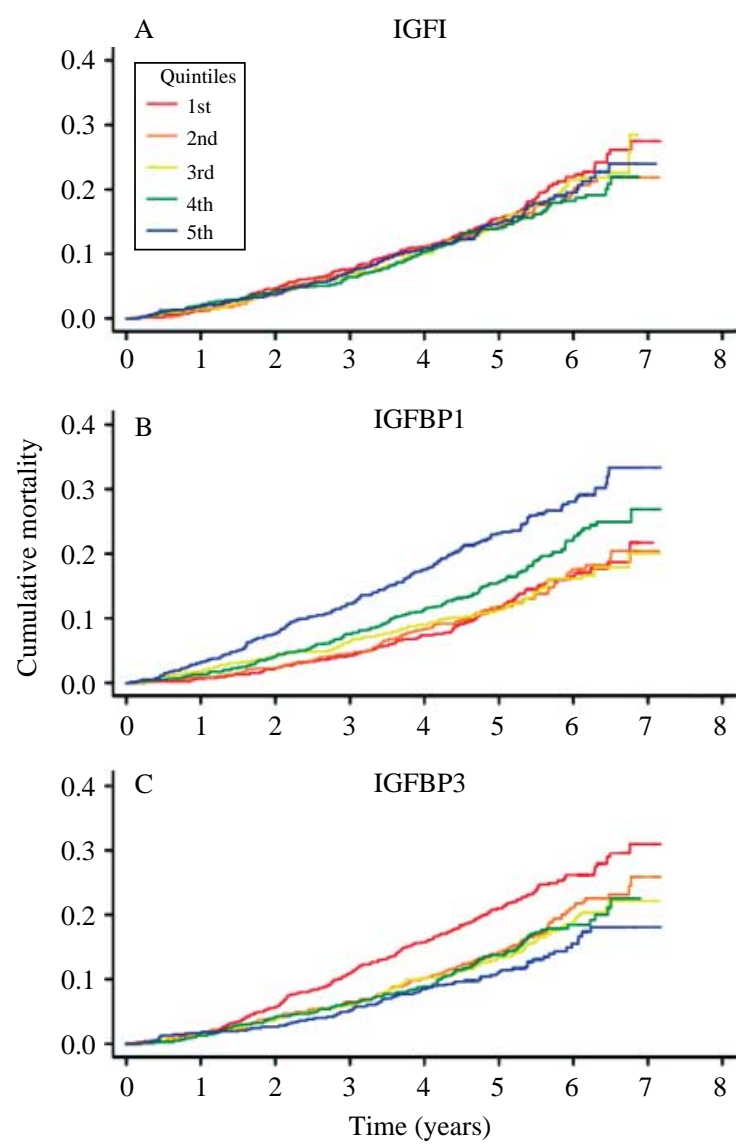

Figure 1 Kaplan-Meier plots showing cumulative mortality according to quintiles of plasma IGF1 (A), IGFBP1 (B) and IGFBP3 (C) in 3983 community-dwelling older men aged 70-89 years at baseline.

\section{Multivariate analyses: IGF1 versus all-cause and CVD-related mortality}

Cox regression models were constructed to show HRs for mortality according to quintiles of IGF1 (Table 2). IGF1 levels did not predict all-cause, CVD-related or non-CVD-related mortality in our cohort, either in univariate analysis or after adjustment for fasting status, age, BMI, waist:hip ratio, smoking, hypertension, dyslipidemia, diabetes, prevalent CVD and medical comorbidities (Table 2).

\section{Multivariate analyses: IGFBP1 versus all-cause and CVD-related mortality}

Men with IGFBP1 levels in the highest two quintiles had increased all-cause mortality in the unadjusted analysis (Table 3). After adjustment for covariates, including fasting status, men with IGFBP1 levels in the highest two quintiles had increased all-cause and CVD-related mortality (Table 3). For IGFBP1 levels in the highest versus lowest quintile, the $\mathrm{HR}$ for CVD mortality was 3.42, while for non-CVD mortality, the HR was
1.40 (Table 3). The trends remained significant when men who were not fasting were excluded from the analysis, but adjusted HR for highest versus lowest quintile of IGFBP1 was lower (all-cause mortality: $P$ for trend $<0.001, \mathrm{HR}=1.58$ (95\% confidence interval, $\mathrm{CI}=1.15-2.16)$; $\mathrm{CVD}$ mortality: $P$ for trend $=0.02$, $\mathrm{HR}=1.85$ (1.06-3.23) and non-CVD mortality: $P$ for trend $<0.001, \mathrm{HR}=1.32(0.91-1.91))$.

\section{Multivariate analyses: IGFBP3 versus overall and CVD-related mortality}

In univariate analysis, all-cause mortality in men with IGFBP3 levels in the lowest two quintiles was increased (Table 4). After adjustment for covariates, all-cause mortality was increased in men with IGFBP 3 levels in the lowest versus highest quintile of values $(\mathrm{HR}=1.57)$ (Table 4). Men with IGFBP3 levels in the lowest quintile had higher CVD and non-CVD mortality compared with men in the highest quintile $(\mathrm{HR}=1.72$ and 1.43 respectively), despite the overall trends being less clear.

\section{Associations of IGFBPI and IGFBP3 with mortality are not attenuated by IGF1}

When IGF1 was included in a multivariate model adjusting for age, BMI, waist:hip ratio, smoking, fasting status, dyslipidemia, hypertension and medical comorbidities, the association of higher IGFBP1 with all-cause mortality was not attenuated $(\mathrm{Q} 5$ versus $\mathrm{Q} 1$ : $\mathrm{HR}=1.98$, $95 \% \mathrm{CI}=1.52-2.57$, with IGF1 included in model: $\mathrm{HR}=2.02,95 \% \mathrm{CI}=1.55-2.63)$. The association of IGFBP1 with CVD-related mortality was similarly unaffected by inclusion of IGF1 into the multivariate

Table 2 IGF1 and all-cause mortality, CVD mortality and non-CVD mortality. Cox regression models showing association of plasma IGF1 by quintiles to all-cause mortality, CVD mortality and non-CVD mortality in older men. Quintiles were 1.6-94.1 ng/ml, 94.2-121 ng/ml, 122-146 ng/ml, 147-184 $\mathrm{ng} / \mathrm{ml}$ and $185-738 \mathrm{ng} / \mathrm{ml}$ respectively.

\begin{tabular}{|c|c|c|c|}
\hline \multirow[b]{2}{*}{ Quintile } & \multirow{2}{*}{$\begin{array}{c}\text { All-cause } \\
\text { mortality } \\
\mathrm{HR}(95 \% \mathrm{Cl})\end{array}$} & \multicolumn{2}{|c|}{ Cause-specific mortality } \\
\hline & & $\begin{array}{c}\text { CVD } \\
\operatorname{HR}(95 \% \mathrm{Cl})\end{array}$ & $\begin{array}{c}\text { Non-CVD } \\
\text { HR }(95 \% \mathrm{Cl})\end{array}$ \\
\hline \multicolumn{4}{|c|}{ Univariate } \\
\hline 1 & 1.00 & 1.00 & 1.00 \\
\hline 2 & $0.89(0.70-1.12)$ & $1.01(0.67-1.52)$ & $0.83(0.63-1.10)$ \\
\hline 3 & $0.93(0.74-1.16)$ & $1.10(0.73-1.64)$ & $0.85(0.64-1.13)$ \\
\hline 4 & $0.86(0.68-1.09)$ & $1.10(0.74-1.65)$ & $0.76(0.57-1.01)$ \\
\hline 5 & $0.91(0.72-1.16)$ & $1.22(0.82-1.81)$ & $0.78(0.58-1.04)$ \\
\hline$P$ value & 0.772 & 0.868 & 0.334 \\
\hline \multicolumn{4}{|l|}{ Adjusted $^{a}$} \\
\hline 1 & 1.00 & 1.00 & 1.00 \\
\hline 2 & $0.90(0.71-1.13)$ & $1.02(0.68-1.53)$ & $0.84(0.63-1.11)$ \\
\hline 3 & $0.98(0.78-1.24)$ & $1.16(0.78-1.74)$ & $0.90(0.68-1.19)$ \\
\hline 4 & $0.90(0.72-1.14)$ & $1.15(0.77-1.73)$ & $0.80(0.60-1.07)$ \\
\hline 5 & $0.94(0.74-1.19)$ & $1.21(0.81-1.81)$ & $0.81(0.61-1.10)$ \\
\hline$P$ value & 0.857 & 0.845 & 0.542 \\
\hline
\end{tabular}

$P$ values are shown for overall trends.

adjusted for age, BMI, waist:hip ratio, smoking, fasting status, dyslipidemia, hypertension and medical comorbidities. 
Table 3 IGFBP1 and all-cause mortality, CVD mortality and non-CVD mortality. Cox regression models showing association of plasma IGFBP1 by quintiles to all-cause mortality, CVD mortality and non-CVD mortality in older men. Quintiles were $0.3-10.1 \mathrm{ng} / \mathrm{ml}, 10.2-17.6 \mathrm{ng} / \mathrm{ml}$, $17.7-26.5 \mathrm{ng} / \mathrm{ml}, 26.6-39.6 \mathrm{ng} / \mathrm{ml}$ and $39.7-175 \mathrm{ng} / \mathrm{ml}$ respectively.

\begin{tabular}{|c|c|c|c|}
\hline \multirow[b]{2}{*}{ Quintile } & \multirow{2}{*}{$\begin{array}{c}\text { All-cause } \\
\text { mortality } \\
\mathrm{HR}(95 \% \mathrm{Cl})\end{array}$} & \multicolumn{2}{|c|}{ Cause-specific mortality } \\
\hline & & $\begin{array}{c}\text { CVD } \\
\mathrm{HR}(95 \% \mathrm{Cl})\end{array}$ & $\begin{array}{c}\text { Non-CVD } \\
\text { HR }(95 \% \mathrm{Cl})\end{array}$ \\
\hline \multicolumn{4}{|c|}{ Univariate } \\
\hline 1 & 1.00 & 1.00 & 1.00 \\
\hline 2 & $1.00(0.77-1.31)$ & $1.88(1.16-3.05)$ & $0.74(0.54-1.02)$ \\
\hline 3 & $1.00(0.77-1.31)$ & $1.66(1.01-2.72)$ & $0.80(0.58-1.09)$ \\
\hline 4 & $1.38(1.08-1.77)$ & $1.98(1.23-3.19)$ & $1.18(0.88-1.57)$ \\
\hline 5 & $2.01(1.59-2.53)$ & $3.09(1.97-4.84)$ & $1.57(1.19-2.06)$ \\
\hline$P$ value & $<0.001$ & $<0.001$ & $<0.001$ \\
\hline \multicolumn{4}{|c|}{ Adjusted ${ }^{\mathrm{a}}$} \\
\hline 1 & 1.00 & 1.00 & 1.00 \\
\hline 2 & $1.08(0.82-1.41)$ & $2.08(1.23-3.51)$ & $0.76(0.55-1.06)$ \\
\hline 3 & $1.11(0.84-1.47)$ & $1.97(1.14-3.38)$ & $0.82(0.58-1.15)$ \\
\hline 4 & $1.42(1.09-1.86)$ & $2.26(1.30-3.91)$ & $1.12(0.82-1.54)$ \\
\hline 5 & $1.98(1.52-2.57)$ & $3.42(2.03-5.77)$ & $1.40(1.03-1.90)$ \\
\hline$P$ value & $<0.001$ & $<0.001$ & $<0.001$ \\
\hline
\end{tabular}

$P$ values are shown for overall trends.

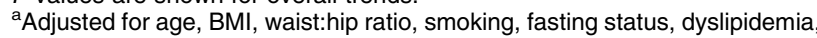
hypertension and medical comorbidities.

model (data not shown). The association of lower IGFBP3 with all-cause mortality appeared to be strengthened by the inclusion of IGF 1 in the multivariate model $(\mathrm{Q} 1$ versus $\mathrm{Q} 5$ : $\mathrm{HR}=1.57,95 \%$ $\mathrm{CI}=1.23-2.01$, with IGF1 included: $\mathrm{HR}=1.85,95 \%$ $\mathrm{CI}=1.38-2.47)$. The association of lower IGFBP 3 with CVD-related mortality was also greater when IGF1 was included ( $Q 1$ versus $\mathrm{Q} 5: \mathrm{HR}=1.72,95 \% \mathrm{CI}=1.12-2.63$, with IGF1 included: $\mathrm{HR}=2.51,95 \% \mathrm{CI}=1.55-4.06$ ).

\section{Sensitivity analyses}

IGF1, IGFBP1 and IGFBP3 levels were comparable in non-diabetic and diabetic men (see Supplementary Table 2, and section on supplementary data given at the end of this article). Men with diabetes receiving insulin treatment had lower IGF1 and IGFBP3 levels and higher IGFBP1 levels (Supplementary Table 2, see section on supplementary data given at the end of this article). HR for all-cause mortality according to quintiles of IGFBP1 remained consistent after men receiving insulin were excluded, or when all men with diabetes were excluded (see Supplementary Table 3, and section on supplementary data given at the end of this article). Similarly, results for IGFBP1 versus CVD and non-CVD mortality, and results for IGFBP 3 versus allcause, CVD and non-CVD mortality were not altered by exclusion of men receiving insulin or all men with diabetes (data not shown).

\section{Discussion}

In a large cohort of community-dwelling older men, we found that increased IGFBP1 and decreased IGFBP3 independently and significantly predicted increased all-cause mortality. Increased IGFBP1 also significantly predicted increased cardiovascular mortality, whereas total IGF1 level was not associated with mortality. Associations of IGFBP1 and IGFBP3 with all-cause mortality were not attenuated by adjustment for IGF1 levels or by exclusion of men with diabetes.

Recent studies of IGF1, IGFBP1 and IGFBP 3 with the outcome of mortality are summarised for comparison in Table 5. Several recent studies specified the use of acid-ethanol extraction to dissociate IGF1 and remove IGFBPs prior to assay of total IGF1 $(13,15,16,20)$. Laughlin et al. (13) reported that lower IGF1 was associated with increased IHD mortality in adults from the Rancho Bernardo study. Roubenoff et al. (15) in a smaller cohort of adults, reported reduced HR for allcause mortality with higher IGF1. However, Saydah et al. (16) in a study of 6061 adults aged $\geq 20$ years from the Third National Health and Nutrition Survey (NHANES III), found no association of IGF1 level with mortality. Recently, van Bunderen et al. (20) reported a U-shaped association between IGF1 and CVD-related mortality in the Amsterdam study.

Friedrich et al. (14) used acid pretreatment and found that IGF1 level in the lowest 10\% predicted higher allcause and CVD-related mortality in men across ages. Other studies have not shown any association of total IGF1 level with mortality $(17,18)$. By contrast, Andreassen et al. (19) reported higher all-cause mortality for IGF1 in the highest quintile. Therefore, the existing literature is not conclusive, being divided among studies associating lower IGF1 with mortality

Table 4 IGFBP3 and all-cause mortality, CVD mortality and non-CVD mortality. Cox regression models showing association of plasma IGFBP3 by quintiles to all-cause mortality, CVD mortality and nonCVD mortality in older men. Quintiles were $603-3000 \mathrm{ng} / \mathrm{ml}$, $3010-3550 \mathrm{ng} / \mathrm{ml}, \quad 3560-4010 \mathrm{ng} / \mathrm{ml}, \quad 4020-4520 \mathrm{ng} / \mathrm{ml}$ and $4530-7600 \mathrm{ng} / \mathrm{ml}$ respectively.

\begin{tabular}{|c|c|c|c|}
\hline \multirow[b]{2}{*}{ Quintile } & \multirow{2}{*}{$\begin{array}{c}\text { All-cause } \\
\text { mortality } \\
\mathrm{HR}(95 \% \mathrm{Cl})\end{array}$} & \multicolumn{2}{|c|}{ Cause-specific mortality } \\
\hline & & $\begin{array}{c}\text { CVD } \\
\operatorname{HR}(95 \% \mathrm{Cl})\end{array}$ & $\begin{array}{c}\text { Non-CVD } \\
\mathrm{HR}(95 \% \mathrm{Cl})\end{array}$ \\
\hline \multicolumn{4}{|l|}{ Univariate } \\
\hline 1 & $1.87(1.47-2.37)$ & $2.02(1.33-3.06)$ & $1.72(1.28-2.32)$ \\
\hline 2 & $1.34(1.04-1.72)$ & $1.50(0.97-2.32)$ & $1.25(0.92-1.71)$ \\
\hline 3 & $1.22(0.94-1.58)$ & $1.14(0.72-1.82)$ & $1.25(0.92-1.72)$ \\
\hline 4 & $1.24(0.95-1.61)$ & $1.46(0.94-2.28)$ & $1.12(0.81-1.55)$ \\
\hline 5 & 1.00 & 1.00 & 1.00 \\
\hline$P$ value & $<0.001$ & 0.006 & 0.003 \\
\hline \multicolumn{4}{|l|}{ Adjusted $^{\mathrm{a}}$} \\
\hline 1 & $1.57(1.23-2.01)$ & $1.72(1.12-2.63)$ & $1.43(1.06-1.95)$ \\
\hline 2 & $1.27(0.98-1.63)$ & $1.43(0.91-2.25)$ & $1.16(0.85-1.59)$ \\
\hline 3 & $1.24(0.95-1.61)$ & $1.19(0.74-1.92)$ & $1.24(0.90-1.70)$ \\
\hline 4 & $1.28(0.98-1.67)$ & $1.55(0.99-2.43)$ & $1.13(0.81-1.57)$ \\
\hline 5 & 1.00 & 1.00 & 1.00 \\
\hline$P$ value & 0.007 & 0.096 & 0.192 \\
\hline
\end{tabular}

$P$ values are shown for overall trends.

${ }^{a}$ Adjusted for age, BMI, waist:hip ratio, smoking, fasting status, dyslipidemia, hypertension and medical comorbidities. 


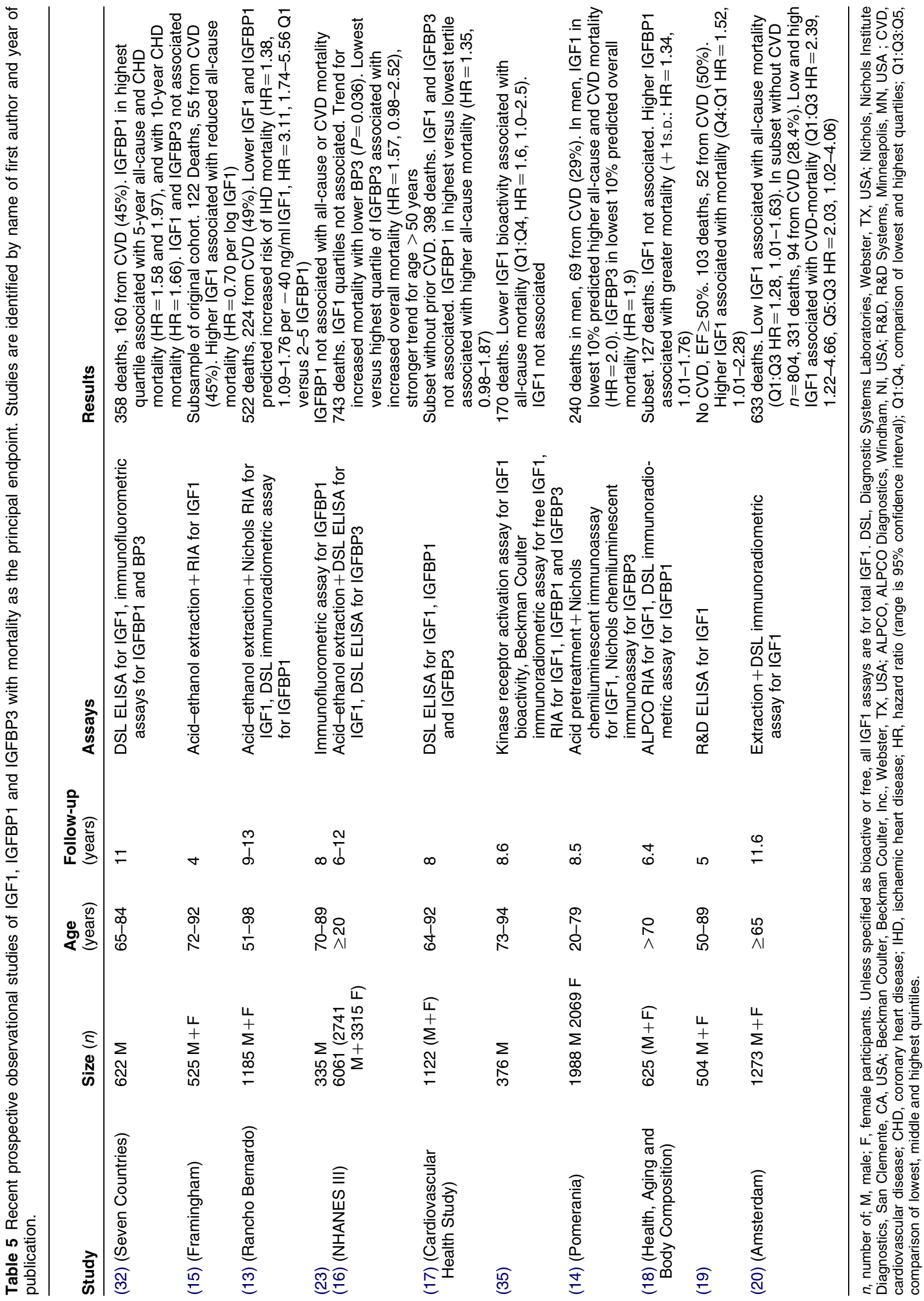


(13-15), several negative studies (16-18) and studies with contrasting results $(19,20)$. In prospective analyses of this type, power to detect associations is dependent on the number of outcome events. Given the size of our cohort and the large number of allcause and CVD deaths that occurred, we would have expected to detect comparable associations of IGF1 with mortality in either direction. Therefore, our study provides additional evidence that in communitydwelling older men, as in healthy adults from NHANES III, total circulating IGF1 does not predict mortality.

Lower IGFBP1 has been associated with insulin resistance and adverse cardiovascular risk profiles, and with macrovascular disease in the setting of type 2 diabetes $(22,24,31)$. However, contrasting associations of IGFBP1 with mortality have been reported (Table 5). Laughlin et al. (13) reported increased IHD mortality in middle-aged and older men with IGFBP1 in the lowest quintile from the Rancho Bernardo study. Kalme et al. (23) found no association of IGFBP1 with mortality. However, Kaplan et al. (17) reported an association of higher IGFBP1 with mortality, which did not reach statistical significance. $\mathrm{Hu}$ et al. (18) reported that higher IGFBP1 was associated with all-cause mortality, and Harrela et al. (32) reported higher IGFBP1 predicted all-cause and coronary heart disease mortality. Despite lower IGFBP1 levels being associated with less favourable indices of cardiovascular risk and increased odds of metabolic syndrome, we found no evidence that reduced IGFBP1 levels predicted CVD mortality; in fact, the contrary trend was present. Our results clearly identify older men with higher IGFBP1 levels to be at greatest risk of death from any cause and also from CVD.

While the majority of circulating IGF1 is bound to IGFBP3 (2), there are relatively fewer data exploring the relationship of IGFBP3 with mortality. Friedrich et al. (14) reported that men in the lowest decile of IGFBP3 experienced increased all-cause mortality. Saydah et al. (16) reported a non-significant trend for increased allcause mortality in men with IGFBP3 in the lowest versus highest quartile. We demonstrate that lower IGFBP3 predicted higher all-cause mortality in older men and determined that this extended to both CVD and non-CVD deaths, with men in the lowest quintile at greatest risk. This association was robust to adjustment for IGF1 levels, despite IGF1 and IGFBP3 being closely correlated $(r=0.59)$ in the initial cross-sectional analysis (28).

We acknowledge several limitations of our study. We did not have the opportunity to collect serial blood samples to determine changes in hormone levels over time and we cannot comment on associations in women. The cohort comprised men who returned for assessment and blood sampling from an earlier population-based sample (25), and the overall mortality rate during 5.2 years of follow-up was $17 \%$. Therefore, a 'healthy survivor' effect is possible, which would make our results more applicable to generally healthier community-dwelling older men. We did not attempt to measure 'free' IGF1 levels either by immunoassay or ultracentrifugation $(33,34)$. A recently reported bioassay based on activation of the IGF1-specific kinase receptor may provide a means of assessing circulating IGF1 bioactivity (35). In that study, lower IGF1 bioactivity was associated with all-cause mortality (Table 5). There was a correlation between IGF1 bioactivity and total IGF1 levels $(r=0.49)$ (35). However, this bioassay is not in general use at present.

We used EDTA plasma for assays in our entire cohort, avoiding potential discordance from mixing sera and plasma samples. We used an assay for estimating total IGF1, which uses acid pretreatment followed by inhibition of binding rather than ethanol extraction of IGFBPs. Even so, our results concur with those of Saydah et al. (16) from NHANES III, which used an acid-ethanol extraction to assay IGF1. As expected, mean IGF1 levels in our men were lower than in middleaged adults but comparable to results from men of comparable age $(16,17)$. We did not use specific thresholds of IGF1, IGFBP1 and IGFBP3 derived from studies performed in sera or in different populations, instead conducting our analyses according to quintiles of hormone levels. Therefore, we believe that the lack of association of IGF1 levels with mortality is not due to confounding from substrate or assay methodologies.

Of note, waist:hip ratios in this cohort of men were comparable to values reported from the Cardiovascular Health Study (36). Men from the Health In Men Study are predominantly Caucasian in ethnic origin, therefore we did not stratify by ethnic group.

We conclude that total IGF1 levels do not stratify risk for all-cause or CVD mortality in older men. This applies particularly to older men willing and able to participate in research such as our study. In the context of promoting healthy ageing, it remains unclear whether GH supplementation, which raises IGF1 levels, might or might not be of any benefit (37). In light of our findings, future studies of $\mathrm{GH}$ supplementation in older persons should examine for effects of GH on IGF1 bioactivity and on levels of IGFBP1 and IGFBP3, in addition to monitoring levels of total IGF1. Consideration might also be given to examining actions of $\mathrm{GH}$ on extrahepatic $\mathrm{GH}$ receptors, distinct from the regulation of liver IGF1 production (2).

We propose three explanations for the finding that higher IGFBP1 predicts mortality which was not accounted for by IGF1 levels. First, higher IGFBP1 levels may provide increased binding sites for circulating IGF1 not already bound in ternary complexes with IGFBP3 and ALS, thus reducing IGF1 bioavailability $(2,21)$. Second, higher IGFBP1 levels may be a marker for underlying conditions which increase mortality risk. Third, IGFBP1 may exert direct effects independently of IGF1 by binding cell surface integrins 
which activate downstream cellular signalling pathways (for review, see (38)). These effects appear to overshadow the association of higher IGFBP1 with reduced prevalence of metabolic syndrome, which would be expected to reduce mortality risk (39). Thus, higher, not lower, IGFBP1 levels are a risk predictor for poorer health outcomes in older men, specifically, for all-cause and CVD-related mortality.

Another noteworthy result from our study is the confirmation that lower IGFBP 3 levels predict mortality. As the HR was increased by adjustment for IGF1, it is unlikely that reduced IGFBP 3 reflects reduced carrying capacity for IGF1 in the circulation, which might limit its availability to tissues. If that were the case, the association should have been attenuated by adjustment for IGF1. We cannot discount the possibility that lower IGFBP3 levels might have been a marker for higher free or bioactive IGF1, or for underlying conditions increasing mortality risk. There are several lines of evidence suggesting that IGFBP3 exerts biological effects independently of the IGF1/IGF1 receptor axis (for review, see (40)). In vitro, IGFBP 3 can inhibit or stimulate growth of different cell types in an IGF1-independent fashion, binding to a putative cell surface receptor to interact with epidermal growth factor receptor, p38 MAPK and transforming growth factor $\beta$ signalling pathways (40). IGFBP 3 may also regulate apoptosis and interfere with NF- $\kappa B$ function (40). Therefore, it is plausible that a relative lack of circulating IGFBP 3 could impede cellular functions important for survival.

In summary, plasma IGF1 was not associated with mortality in older men; however, higher IGFBP1 and lower IGFBP3 levels predicted mortality. Additional research is required to determine whether these associations are causal, and if so, to clarify the underlying mechanisms by which IGFBP1 and IGFBP3 levels modulate mortality risk, and whether this occurs independently of IGF1.

\section{Supplementary data}

This is linked to the online version of the paper at http://dx.doi.org/ 10.1530/EJE-11-0059.

\section{Declaration of interest}

The authors declare that there is no conflict of interest that could be perceived as prejudicing the impartiality of the research reported.

\section{Funding}

Hormone assays were funded by Project Grant 513823 from the National Health and Medical Research Council of Australia (NHMRC). The Health In Men Study was funded by NHMRC Project Grants 279408, 379600 and 403963. B B Yeap is recipient of a Clinical Investigator Award from the Sylvia and Charles Viertel Charitable Foundation, New South Wales, Australia. P E Norman is supported by NHMRC Practitioner Fellowship 458505.

\section{Acknowledgements}

We thank Sylvia Johnson of DSL Australia for her specialist help in setting up the IGF1 and IGFBP assays, Johnson Setoh and Seamus Duffy for excellent technical assistance, and the staff of Shenton Park Hospital for their help with the study. We especially thank all the men and staff who participated in the Western Australian Abdominal Aortic Aneurysm Program and the Health In Men Study, and acknowledge assistance received from the Data Linkage Unit of the Health Department of Western Australia.

\section{References}

1 Sherlock M \& Toogood AA. Aging and the growth hormone/ insulin like growth factor-I axis. Pituitary 2007 10 189-203. (doi:10.1007/s11102-007-0039-5)

2 Ohlsson C, Mohan S, Sjogren K, Tivesten A, Isgaard J, Isaksson O, Jansson J-O \& Svensson J. The role of liver-derived insulin-like growth factor-I. Endocrine Reviews 200930 494-535. (doi:10. 1210/er.2009-0010)

3 Colao A, Di Somma C, Spiezia S, Savastano S, Rota F, Savanelli MC \& Lombardi G. Growth hormone treatment on atherosclerosis: results of a 5-year open, prospective, controlled study in male patients with severe growth hormone deficiency. Journal of Clinical Endocrinology and Metabolism 200893 3416-3424. (doi:10. 1210/jc.2007-2810)

4 Janssen JAMJL, Stolk RP, Pols HAP, Grobbee DE \& Lamberts SWJ. Serum total IGF-1, free IGF-1, and IGFBP-1 levels in an elderly population: relation to cardiovascular risk factors and disease. Arteriosclerosis, Thrombosis, and Vascular Biology 199818 277-282.

5 Colangelo LA, Liu K \& Gapstur SM. Insulin-like growth factor-1, insulin-like growth factor binding protein-3, and cardiovascular disease risk factors in young black men and white men: the CARDIA male hormone study. American Journal of Epidemiology 2004160 750-757. (doi:10.1093/aje/kwh289)

6 Colao A, Di Somma C, Cascella T, Pivonello R, Vitale G, Grasso LFS, Lombardi G \& Savastano S. Relationships between serum IGF-I levels, blood pressure, and glucose tolerance: an observational, exploratory study in 404 subjects. European Journal of Endocrinology 2008159 389-397. (doi:10.1530/EJE-08-0201)

7 Vasan RS, Sullivan LM, D'Agostino RB, Roubenoff R, Harris T, Sawyer DB, Levy D \& Wilson PW. Serum insulin-like growth factor 1 and risk for heart failure in elderly individuals without a previous myocardial infarction: The Framingham Heart Study. Annals of Internal Medicine $2003139642-648$.

8 Juul A, Scheike T, Davidsen M, Gyllenborg J \& Jorgensen T. Low serum insulin-like growth factor 1 is associated with increased risk of ischemic heart disease: a population-based case-control study. Circulation 2002106 939-944. (doi:10. 1161/01.CIR.0000027563.44593.CC)

9 Johnsen SP, Hundborg HH, Sorensen HT, Orskov H, Tjonneland A, Overvad K \& Jorgensen JO. Insulin-like growth factor (IGF) I, -II and IGF binding protein-3 and risk of ischemic stroke. Journal of Clinical Endocrinology and Metabolism 200590 5937-5941. (doi:10.1210/jc.2004-2088)

10 Kaplan RC, McGinn AP, Pollak MN, Kuller LH, Strickler HD, Rohan TE, Cappola AR, Xue X \& Psaty BM. Association of total IGF-1, IGFBP-1 and IGFBP-3 levels with incident coronary events and ischemic stroke. Journal of Clinical Endocrinology and Metabolism 200792 1319-1325. (doi:10.1210/jc.2006-1631)

11 Fischer F, Schulte H, Mohan S, Tataru MC, Kohler E, Assmann G \& von Eckardstein A. Associations of insulin-like growth factors, insulin-like growth factor binding proteins and acid-labile subunit with coronary heart disease. Clinical Endocrinology 200461 595-602. (doi:10.1111/j.1365-2265.2004.02136.x)

12 Kawachi S, Takeda N, Sasaki A, Kokubo Y, Takami K, Sarui H, Hayashi M, Yamakita N \& Yasuda K. Circulating insulin-like growth factor-1 and insulin-like growth factor binding protein-3 
are associated with early carotid atherosclerosis. Arteriosclerosis, Thrombosis, and Vascular Biology 2005 25 617-621. (doi:10. 1161/01.ATV.0000154486.03017.35)

13 Laughlin GA, Barrett-Connor E, Criqui MH \& Kritz-Silverstein D. The prospective association of serum insulin-like growth factor I (IGF-I) and IGF-binding protein-1 levels with all cause and cardiovascular mortality in older adults: the Rancho Bernardo study. Journal of Clinical Endocrinology and Metabolism 200489 114-120. (doi:10.1210/jc.2003-030967)

14 Friedrich N, Haring R, Nauck M, Ludemann J, Rosskopf D, SpilckeLiss E, Felix SB, Dorr M, Brabant G, Volzke H \& Wallaschofski H. Mortality and serum insulin-like growth factor (IGF)-I and IGF binding protein 3 concentrations. Journal of Clinical Endocrinology and Metabolism 2009 94 1732-1739. (doi:10.1210/jc.2008-2138)

15 Roubenoff R, Parise H, Payette HA, Abad LW, D'Agostino R, Jacques PF, Wilson PWF, Dinarello CA \& Harris TB. Cytokines, insulin-like growth factor 1 , sarcopenia, and mortality in very old community-dwelling men and women: the Framingham study. American Journal of Medicine 2003115 429-435. (doi:10.1016/j. amjmed.2003.05.001)

16 Saydah S, Graubard B, Ballard-Barbash R \& Berrigan D. Insulinlike growth factors and subsequent risk of mortality in the United States. American Journal of Epidemiology $2007 \mathbf{1 6 6} 518-526$. (doi:10.1093/aje/kwm124)

17 Kaplan RC, McGinn AP, Pollak MN, Kuller L, Strickler HD, Rohan TE, Xue XN, Kritchevsky SB, Newman AB \& Psaty BM. Total insulinlike growth factor 1 and insulinlike growth factor binding protein levels, functional status, and mortality in older adults. Journal of the American Geriatrics Society $2008 \mathbf{5 6}$ 652-660. (doi:10.1111/j.1532-5415.2007.01637.x)

$18 \mathrm{Hu}$ D, Pawlikowska L, Kanaya A, Hsueh W-C, Colbert L, Newman AB, Satterfield S, Rosen C, Cummings SR, Harris TB \& Ziv E. Serum insulin-like growth factor- 1 binding proteins 1 and 2 and mortality in older adults: the health, aging, and body composition study. Journal of the American Geriatrics Society 2009 57 1213-1218. (doi:10.1111/j.1532-5415.2009.02318.x)

19 Andreassen M, Raymond I, Kistorp C, Hildebrandt P, Faber J \& Kristensen LO. IGF1 as a predictor of all cause mortality and cardiovascular disease in an elderly population. European Journal of Endocrinology 2009160 25-31. (doi:10.1530/EJE-08-0452)

20 Van Bunderen CC, van Nieuwpoort IC, van Schoor NM, Deeg DJH, Lips P \& Drent ML. The association of serum insulin-like growth factor-I with mortality, cardiovascular disease, and cancer in the elderly: a population-based study. Journal of Clinical Endocrinology and Metabolism 2010 95 4616-4624. (doi:10.1210/jc.2010-0940)

21 Juul A. Serum levels of insulin-like growth factor I and its binding proteins in health and disease. Growth Hormone and IGF Research 200313 113-170. (doi:10.1016/S1096-6374(03)00038-8)

22 Heald AH, Cruickshank JK, Riste LK, Cade JE, Anderson S, Greenhalgh A, Sampayo J, Taylor W, Fraser W, White A \& Gibson JM. Close relation of fasting insulin-like growth factor binding protein-1 (IGFBP-1) with glucose tolerance and cardiovascular risk in two populations. Diabetologia 200144 333-339. (doi:10.1007/s001250051623)

23 Kalme T, Seppala M, Qiao Q, Koistinen R, Nissinen A, Harrela M, Loukovaara M, Leinonen P \& Tuomilehto J. Sex-hormone-binding globulin and insulin-like growth factor-binding protein-1 as indicators of metabolic syndrome, cardiovascular risk, and mortality in elderly men. Journal of Clinical Endocrinology and Metabolism 2005 90 1550-1556. (doi:10.1210/jc.2004-0762)

24 Kotronen A, Lewitt M, Hall K, Brismar K \& Yki-Jarvinen H. Insulin-like growth factor binding protein 1 as a novel specific marker of hepatic insulin sensitivity. Journal of Clinical Endocrinology and Metabolism 200893 4867-4872. (doi:10. 1210/jc.2008-1245)

25 Norman PE, Flicker L, Almeida OP, Hankey GJ, Hyde Z \& Jamrozik K. Cohort profile: the Health In Men Study (HIMS). International Journal of Epidemiology $2009 \mathbf{3 8} 48-52$. (doi:10. 1093/ije/dyn041)

26 Holman CD, Bass AJ, Rouse IL \& Hobbs MS. Population-based linkage of health records in Western Australia: development of a health services research linked database. Australian and New Zealand Journal of Public Health 199923 453-459. (doi:10.1111/j. 1467-842X.1999.tb01297.x)

27 Charlson ME, Pompei P, Ales KL \& MacKenzie CR. A new method of classifying prognostic comorbidity in longitudinal studies: development and validation. Journal of Chronic Diseases $1987 \mathbf{4 0}$ 373-383. (doi:10.1016/0021-9681(87)90171-8)

28 Yeap BB, Chubb SAP, Ho KKY, Setoh JWS, McCaul KA, Norman PE, Jamrozik K \& Flicker L. Insulin-like growth factor-I and its binding proteins 3 and 1 are differentially associated with metabolic syndrome in older men. European Journal of Endocrinology 2010162 249-257. (doi:10.1530/EJE-09-0852)

29 Fine JP \& Gray RJ. A proportional hazards model for the subdistribution of a competing risk. Journal of the American Statistical Association 199994 496-509. (doi:10.2307/2670170)

30 Greenland S. Modeling and variable selection in epidemiologic analysis. American Journal of Public Health 198979 340-349. (doi:10.2105/AJPH.79.3.340)

31 Heald AH, Siddals KW, Fraser W, Taylor W, Kaushal K, Morris J, Young RJ, White A \& Gibson JM. Low circulating levels of insulinlike growth factor binding protein-1 (IGFBP1) are closely associated with the presence of macrovascular disease and hypertension in type 2 diabetes. Diabetes $2002512629-2636$. (doi:10.2337/diabetes.51.8.2629)

32 Harrela M, Qiao Q, Koistinen R, Tuomilehto J, Nissinen A, Seppala M \& Leinonen P. High serum insulin-like growth factor binding protein-1 is associated with increased cardiovascular mortality in elderly men. Hormone and Metabolic Research 200234 144-149. (doi:10.1055/s-2002-23198)

$33 \mathrm{Yu}$ H, Mistry J, Nicar MJ, Khosravi MJ, Diamandis A, van Doorn J \& Juul A. Insulin-like growth factors (IGF-I, free IGF-I and IGF-II) and insulin-like growth factor binding proteins (IGFBP-2, IGFBP3, IGFBP-6, and ALS) in blood circulation. Journal of Clinical and Laboratory Analysis 199913 166-172. (doi:10.1002/(SICI)10982825(1999)13:4<166::AID-JCLA5 > 3.0.CO;2-X)

34 Frystyk J, Skjaerbaek C, Dinesen B \& Orskov H. Free insulin-like growth factors (IGF-I and IGF-II) in human serum. FEBS Letters 1994348 185-191. (doi:10.1016/0014-5793(94)00602-4)

35 Brugts MP, van den Beld AW, Hofland LJ, van der Wansem K, van Koetsveld PM, Frystyk J, Lamberts SWJ \& Janssen JAMJL. Low circulating insulin-like growth factor I bioactivity in elderly men is associated with increased mortality. Journal of Clinical Endocrinology and Metabolism 200893 2515-2522. (doi:10.1210/jc.2007-1633)

36 Kizer JR, Biggs ML, Ix JH, Mukamal KJ, Zieman SJ, de Boer IH, Mozaffarian D, Barzilay JI, Strotmeyer ES, Luchsinger JA, Elkind MSV, Longstreth WT, Kuller LH \& Siscovick DS. Measures of adiposity and future risk of ischemic stroke and coronary heart disease in older men and women. American Journal of Epidemiology 2011173 10-25. (doi:10.1093/aje/kwq311)

37 Liu H, Bravata DM, Olkin I, Nayak S, Roberts B, Garber AM \& Hoffman AR. Systematic review: the safety and efficacy of growth hormone in the healthy elderly. Annals of Internal Medicine 2007 146 104-115.

38 Wheatcroft SB \& Kearney MT. IGF-dependent and IGF-independent actions of IGF-binding protein-1 and -2: implications for metabolic homeostasis. Trends in Endocrinology and Metabolism 200920 153-162. (doi:10.1016/j.tem.2009.01.002)

39 Akbaraly TN, Kivimaki M, Ancelin M-L, Barberger-Gateau P, Mura T, Tzourio C, Touchon J, Ritchie K \& Berr C. Metabolic syndrome, its components, and mortality in the elderly. Journal of Clinical Endocrinology and Metabolism 201095 E327-E332. (doi:10.1210/jc.2010-0153)

40 Jogie-Brahim S, Feldman D \& Oh Y. Unraveling insulin-like growth factor binding protein-3 actions in human disease. Endocrine Reviews 200930 417-437. (doi:10.1210/er.2008-0028)

Received 18 February 2011

Accepted 4 March 2011 